\title{
Un parteaguas sobre la historia del catolicismo tercermundista en la Argentina
}

Omar Acha ${ }^{1}$

TOURIS, Claudia. La constelación tercermundista. Catolicismo y cultura politica en la Argentina, 1955-1976. Buenos Aires: Biblos, 2021, 390 p.

Resenha recebida em: 06/12/2021

Resenha aprovada para publicação em: 13/12/2021

Es sabido que en materia de investigación histórica jamás hay una obra definitiva. Las preguntas cambian, los archivos se modifican, las preocupaciones se transforman. Pero cada tanto aparecen libros imprescindibles. Eso no implica que la lectura deba plegarse sin matices a la interpretación propuesta. Supone más bien que su consulta se hace inevitable por la calidad, solidez y alcance logradas. He allí la naturaleza historiográfica de La constelación tercermundista publicada por la historiadora argentina Claudia Touris.

Esta reseña se distribuirá en tres segmentos. El primero sintetiza el contenido del libro. El segundo pondera su valor historiográfico. El tercero propone dos líneas de reflexión sobre cuestiones abiertas por la obra.

El volumen está compuesto por seis capítulos, a los que se añaden una amplia introducción y unas conclusiones. En la "Introducción", la autora declara que la meta de su trabajo es el estudio del catolicismo tercermundista en la Argentina entre 1955 y 1976, con especial énfasis en su incidencia en la cultura política del periodo. El concepto de "cultura política" permite incorporar al análisis "el conjunto de ideas, creencias, mitos, valores, sentimientos, identidades, prácticas y experiencias que conforman la vida política de una sociedad" (p. 17). En otras palabras, se trata de

\footnotetext{
${ }^{1}$ Universidad de Buenos Aires. Consejo Nacional de Investigaciones Científicas y Técnicas.

E-mail: omaracha@gmail.com
} 
mucho más que una historia de las ideas o concepciones de índole teológica, pastoral, ideológica o religiosa.

Esa definición de cultura política permite a la investigadora encarar múltiples dimensiones de la experiencia histórica, a partir de un diagnóstico general válido para todo el lapso estudiado: el descreímiento de la democracia formal, el privilegio de las vías extrainstitucionales de la política, la aparición de las estrategias insurreccionales, los pactos secretos y el militarismo. Aunque esos rasgos pueden prolongarse antes y después de 1945 y 1976, Claudia Touris estudia el modo en que moldean las acciones de los actores en el largo treintenio señalado. De esa cultura política participan, con características propias, dos identidades vigorosas como las vinculadas al peronismo y al catolicismo.

Touris se diferencia de los estudios precedentes sobre los sacerdotes tercermundistas en la Argentina porque su tema excede al sector específico adoptado por esa identificación a fines de la década de 1960. Más que el Movimiento de Sacerdotes para el Tercer Mundo (en adelante, MSTM), la historiadora sigue el recorrido de una "constelación" compuesta por los presbíteros tercermundistas descubriendo la trama donde se conectan con miembros de la jerarquía eclesiástica, laicos, religiosas y un amplio conjunto de individuos y actores de variada índole partícipes de una configuración fluida y dinámica de gran riqueza histórica.

Una de las varias consecuencias de la ampliación del enfoque de investigación consiste en que la noción de constelación neutraliza la dicotomización, estimulada por los aires renovadores del Concilio Vaticano II (1962-1965), entre una nueva generación sacerdotal, inquieta y renovadora, y una jerarquía conservadora e incluso reaccionaria. O una oposición entre, por un lado, un sector atento a la "opción por los pobres" y una lectura socializante del peronismo y, por otro lado, un sector atenido a la defensa del status quo. Tal como es investigado en este libro, el MSTM no es una formación homogénea y regida por una doctrina compacta. Tampoco la jerarquía eclesiástica es completamente inmune a las tendencias que acompañan al Concilio. 
Sobre todo en nuevas diócesis de las provincias que están construyendo recientes estructuras eclesiásticas, las novedades pastorales llegadas desde Roma hallan simpatías de diverso calibre. Así ocurre, por mencionar solo algunos prelados, con Jaime de Nevares (del sureño Neuquén) y Alberto Devoto (de la mesopotámica Goya).

Una constelación como la reconstruida por Touris es incompatible con varias de las interpretaciones tradicionales cuya premisa es la mencionada dicotomización. En efecto, sea que se condene al tercermundismo religioso como una escisión en el seno de la Iglesia que pretende conducirla a fines incompatibles con su esencia, sea que se realice la apología del compromiso social de los presbíteros en oposición a una jerarquía cómplice de los poderes establecidos, tales juicios revelan sus limitaciones cuando el escenario ya no es divisible en dos franjas claras y distintas. En cambio, la autora sigue las trayectorias, las modificaciones y matizaciones en las opiniones, los desacuerdos y discusiones que presentan un escenario realmente dinámico.

El capítulo 1, "El catolicismo argentino entre la crisis con el peronismo y el 'malestar' preconciliar", describe el abigarrado segmento que se prolonga entre el conflicto abierto entre el gobierno peronista y el catolicismo a fines de $1954 \mathrm{y}$ las rearticulaciones producidas en el campo católico desde 1956, cuando comienza a percibirse que la meta de la Revolución Libertadora (1955-1958) de elimiar al peronismo de la vida pública, y sobre todo la persistencia obrera y popular de la "promesa peronista" (en palabras de Silvia Sigal), horadan los consensos interiores a dicho campo. Al respecto, Touris retoma la distinción propuesta por María Estela Spinelli para el antiperonismo posterior a 1955 entre las variantes "tolerante", "radicalizado" y "optimista". Esas diferenciaciones serían también hallables en el catolicismo. El estado de deliberación interna entre sectores en pugna conduce, como señala la autora, a que el segmento prolongado entre 1955 y 1957 verifique una secuencia de pronunciamientos doctrinarios del Episcopado argentino en pos de una unidad cada vez más precaria. 
Otro aspecto relevante, rastreable previamente pero que adquiere mayor visibilidad una vez derrocado el peronismo, es la atención despertada por las experiencias de los "curas obreros", una primicia que suscita interés en la Argentina debido al reconocimiento de que los trabajadores manifestan pública hostilidad hacia una Iglesia acusada de conspirar contra el gobierno que consideraban el más suyo. La novedad interpela la suerte de la Juventud Obrera Católica (JOC), cuyas dificultades para insertarse en la clase trabajadora suscitan debates en el jocismo sobre una consolidada centralidad de la "acción católica" dirigida preferentemente a los sectores medios. Touris plantea el despliegue de un "malestar" que será una precondición de las recepciones de un Concilio que, desde luego, nadie espera en 1959 en que se conoce la convocatoria pontificia. No obstante, hondas preocupaciones, discusiones sobre la pastoral católica y el activismo laical, inciden en unos años sesenta cuyo clima epocal se transforma significativamente. Con buen criterio, Touris se abstiene de imponer a los años ' 50 el ser antecedentes necesarios de unos inexorables años ' 60 . Menciono este rasgo de la narrativa elegida pues tiene la virtud de mantener al público lector atento a los acontecimientos, preservando un interés por seguir la trama.

El capítulo 2 porta el título de "Sociabilidades, debates y conflictos en la Iglesia argentina y posconciliar". El problema inicial enunciado, el que tal vez sostenga la pregunta general del libro, es el de la singular "modernidad" característica de los países latinoamericanos, la que deja huellas en la cultura católica, particularmente respecto de la manera de asumir la secularización de la sociedad. En otras palabras, se trata de evaluar el grado de aceptación alcanzado por la separación de las esferas religiosa y política. El diagnóstico de Touris vigente para el segmento central del siglo $\mathrm{XX}$, en cierta medida emparentado con la tesis de Loris Zanatta sobre la pregnancia del "mito de la nación católica" (en especial en la Iglesia y en las Fuerzas Armadas, pero con alcances más vastos), subraya la relevancia de un "integrismo" de problemática relación con la modernidad. Respecto del periodo vinculado al Concilio 
y sus posterioridades, Touris se diferencia de algunas interpretaciones que afirman para la época una oposición entre un integrismo de derecha y un integrismo de izquierda. Su empeño consiste, por el contrario, en desplegar las tensiones del tercermundismo ante la modernidad.

Claudia Touris pondera las incidencias locales del Concilio Vaticano II, sin cuyas novedades se comprende mal la eficacia para la emergencia del tercermundismo de la I Conferencia Episcopal Latinoamericana reunida en Medellín, Colombia, en 1968. El Concilio suscita variadas reacciones locales, en el ámbito católico pero también más ampliamente en la cultura general. Como lo expresan artículos de la importante revista católica Criterio sobre el acontecimiento conciliar, las discusiones internas al catolicismo no son escasas, tanto, y esto es lo importante para el argumento de Touris, en los sectores más tradicionalistas como en los de orientación preferentemente renovadora.

A propósito del encuentro de Medellín (en el que se refracta el Concilio pero también la enclícica Populorum Progressio, de 1967), se destacan las recepciones locales entre las que subraya la menor incidencia de predisposiciones más pluralistas, una reducción del clericalismo y la formación de "comunidades eclesiales de base", observables por ejemplo en la experiencia brasileña. La "opción por los pobres" de Medellín, la crítica del capitalismo y la injusticia social son, en efecto, interpretados de diferentes maneras. Vinculándose con la relectura del peronismo, la noción de "liberación" se despliega en un proceso de acercamiento a una "justicia social" suficientemente flexible para conectarse con temas marxistas. Por cierto sin estos últimos aspectos, incluso el Episcopado argentino se pronuncia favorable a la "liberación" en su reunión de abril de 1969. También el laicado en sus diferentes expresiones (la tradicional Acción Católica, el sindicalismo cristiano, el Humanismo universitario, las Ligas Agrarias, entre otras) se ve profundamente afectado por las recientes novedades. 
La fluidez de las sociabilidades católicas (un concepto medular en todo el libro de Touris), incrementada en un momento de intersecciones entre diversas orientaciones ideológicas que pocos años antes parecen incomunicables, tornan verosímil el cambio de escenario de los años '60. El golpe de Estado comandado por el general Juan Carlos Onganía en junio de 1966 expande, también en sectores del catolicismo, la opinión de que "el sistema" es incapaz de ser cuestionado de otra manera que a través de la violencia "desde abajo". Las páginas dedicadas a la revista Cristianismo y Revolución (1966-1971) están destinadas a ilustrar esa convicción, pero también a mostrar los pasajes entre múltiples ámbitos de sociabilidad y los debates que les son característicos. Las controversias alcanzan también a los ámbitos eclesiásticos. Para mostrarlos, Touris reconstruye los desacuerdos posconciliares surgidos en Córdoba, Mendoza y Rosario, casos en los cuales, enfatiza la autora, "se advierten desplazamientos, marchas y contramarchas en las ideas y prácticas de los protagonistas: jerarquía eclesiástica, clero y laicos", a la luz de comportamientos "que fueron variando al calor de los acontecimientos" (p. 157).

El capítulo 3, intitulado "La revolución en clave clerical", reconstruye las consecuencias en el espacio religioso católico de las innovaciones identificadas con el Concilio, articulándolas con el acercamiento al peronismo del MSTM. El tema central del capítulo está centrado en la tesis de que así se asiste a la reemergencia, en nuevos términos dados los rasgos epocales, del "cristianismo peronista" que proporciona uno de los ingredientes principales que conduce desde 1950 a la fractura de la alianza del catolicismo argentino con el peronismo. Esa decisión católico-tercermundista por el peronismo, sin embargo, no está presente desde principio, pues en sus primeros pasos se defiende una distancia con los partidos políticos y, más en general, “el poder".

La formación del MSTM en 1968, que logra incorporar a sus filas a alrededor del $10 \%$ del clero nacional, es reconstruida a través del análisis de sus encuentros hasta 1973, el estudio de sus publicaciones y declaraciones, mas no en una aproximación solo interna. Touris inscribe esas novedades en un clima de época, en el que por 
ejemplo se explica la adhesión, más o menos plástica, a un vocabulario marxista ligado a la "revolución" y al "Hombre Nuevo". La adopción de ese vocabulario en cuya credibilidad tiene un papel central la Revolución Cubana y ciertamente la figura mítica del cura guerrillero Camilo Torres, se ve pronto tamizada por las dualidades próximas al idioma revisionista (pueblo vs. antipueblo, colonia vs. patria, mayorías vs. élites, etc.) asociado al peronismo. De las injusticias e injurias derivadas de la opresión de un aspecto de la dualidad sobre el otro se sostiene, en el discurso de tercermundismo católico, el ministerio profético atribuido a la función sacerdotal. Entonces se produce una fusión entre religión y política en la que el sacerdote posee un lugar central e insustituible.

Las caracterizaciones genéricas propuestas por Touris son compatibles con sutiles análisis empíricos. El "cristianismo peronista" y el "profetismo utópico", por caso, son rastreados en actores históricos con nombre y apellido, con trayectos particulares. El propio MSTM revela sus fracturas, sus alternativas encontradas, las que serán puestas a prueba cuando el regreso del peronismo fuerce a adoptar posturas ante la lucha armada (una opción muy minoritaria en el tercermundismo religioso argentino), el peronismo y el socialismo. No es por azar que tras el VI Encuentro Nacional del MSTM realizado en Córdoba, en agosto de 1973, cuando las disputas internas del peronismo regresado al gobierno recrudecen, el movimiento se fragmenta y pierde consistencia colectiva.

El capítulo 4 sobre los “curas villeros” y el Movimiento Villero Peronista es de lo mejor que se ha escrito, no solo sobre lo que anuncia el título, sino de la historia de las villas miseria y la política local en esos espacios para el periodo 1966-1976. La cuestión de las villas miseria es un nudo principal en la actuación de los sacerdotes tercermundistas y adquiere con la figura y asesinato del presbítero Carlos Mugica, en 1974, una significación perdurable. De hecho, la primera declaración colectiva del MSTM dirigida al gobierno de Onganía, a fines de 1968, está asociada a una protesta por el plan de erradicación de villas miseria. Touris estudia las innovaciones 
pastorales y las elaboraciones teológicas (la "teología del pueblo" o la "pastoral popular") asociadas entre otros al contexto villero, así como las prácticas ligadas a las creencias populares. La entronización de la virgen María y las peregrinaciones a la Catedral de Luján son instancias de la acción ligadas a una idea de los pobres en clave "mesiánica", anti-institucional pero a la vez clerical.

El Capítulo 5, "Entre María y Marianne: los trayectos de las religiosas tercermundistas", es el más original del libro, pues hasta el momento la atención se había concentrado casi exclusivamente en el MSTM, es decir, en los sacerdotes que para el catolicismo son por definición varones. Touris propone incorporar a las religiosas que adhieren al movimiento en los términos de un "tercermundismo temperado". El lugar subordinado de las mujeres en la Iglesia no sufre mutaciones decisivas durante el periodo estudiado, aunque sí se reconoce la necesidad de cambios. La clausura en congregaciones deja de ser destino para habilitar prácticas de apoyo en el apostolado. El clima del Concilio conduce a ampliar la educación de las religiosas, antes en general restringida a las normativas internas de las congregaciones. La salida al exterior social involucra, considerada en perspectiva de amplia duración, una importante transformación del lugar de las mujeres atribuido por el tradicionalismo católico en el lugar de pasividad que la autora describe como de "servidoras y esposas de Cristo-Iglesia/émulas de María" (p. 280). Basada en la publicación periódica Vida en Fraternidad y en entrevistas orales, Claudia Touris reconstruye, reconociendo las restricciones de un estudio pionero que nuevas investigaciones pueden profundizar, los itinerarios de religiosas argentinas y extranjeras (francesas), tensionadas entre el modelo de María ya referido y el de Marianne como la mujer en tanto agente autónomo de la política y de lo público. Desgarradas entre el tradicionalismo y la modernidad, esas mujeres son narradas como partícipes de sus propias vidas, una experiencia contradictoria que este capítulo logra rescatar del olvido. 
El capítulo 6 estudia las derivas del tercermundismo católico entre 1969 y 1976. Analiza una época de politización de la constelación, sus debates y la declinación perceptible hacia 1973 (cuando según se ha señalado, comienza la descomposición del MSTM como colectivo), prolongándose en los tormentosos años precedentes al golpe dictatorial de 1976. La insurrección popular del "Cordobazo" de mayo de 1969, la aparición de Montoneros (con el hecho fundacional de la ejecución del ex presidente de facto Pedro E. Aramburu en 1970) y las perspectivas de un regreso del peronismo en el escenario abierto por el Gran Acuerdo Nacional, suscitan nuevos disensos en un panorama católico que experimenta sus propias metamorfosis. En el capítulo se reconstruyen con detalle las discusiones en el seno de la jerarquía eclesiástica a propósito de catolicismo tercermundista en el que nuevamente se advierte la presencia de posturas encontradas.

Son particularmente reveladoras las divergencias desarrolladas en los debates del clero de Buenos Aires, en 1971, donde la vocación condenatoria de monseñor Adolfo Tortolo hacia el tercermundismo es contenida por monseñor Juan C. Aramburu, no porque éste simpatice con el tercermundismo, sino porque el Vaticano desaconseja sanciones de la índole requerida por Tortolo y quien toma la palabra crítica del MSTM, el clérigo tomista Julio Meinvielle. La postura tercermundista es defendida por el sacerdote Jorge Vernazza. Luego de un análisis de las elaboraciones teológicas implicadas en el enfoque tercermundista, sobre todo a propósito de los escritos de Lucio Gera, la autora plantea algunas hipótesis sobre la declinación y repliegue de la "constelación tercermundista".

Las hipótesis comprenden aspectos contingentes, como el cambio de signo en el Consejo Episcopal Latinoamericano hacia una reducción del apoyo al catolicismo liberacionista en toda la región, pero otros inherentes al propio tercermundismo, como sus enfrentamientos con la jerarquía eclesiástica (sobre todo los sacerdotes del interior del país tienden a ser más heterodoxos al respecto), las autoridades militares y las conexiones que, así sea de modo minoritario, tienen con algunas organizaciones 
guerrilleras. Se trataría, conjetura Touris, de una "intransigencia" deudora tanto del "nacional-catolicismo" como del "cristianismo peronista" reeditado. No obstante sus aperturas a la religiosidad popular y a una teología "del pueblo", según la autora el MSTM continúa adhiriendo a una "vertiente populista-culturalista de conducción clerical" afín al de la Iglesia Católica argentina (p. 362). En otras palabras, las dificultades para lidiar con los desafíos de la modernidad, la asunción de un clericalismo ajeno a una distinción de esferas de lo político y lo religioso, la adhesión al estilo peronista de conducción y las ambiguas relaciones con las estrategias de transformación radical, conspiran contra la proyección del Movimiento.

Además de un relevamiento conceptual e interpretativo de la bibliografía preexistente, del uso de fuentes escritas de diversa naturaleza, Claudia Touris realiza un largo y paciente trabajo de recolección de entrevistas orales sin las cuales aspectos de esa historia hubieran permanecido desconocidos tal vez para siempre. La autora realiza una tarea magistral en el análisis de las entrevistas. No se pliega ingenuamente a las palabras recogidas ni les impone un juicio externo. Las incorpora con las complejidades de la memoria social e individual y el reconocimiento de que una entrevista es también un dispositivo pensable como un acontecimiento.

El libro de Claudia Touris es un solvente estudio histórico. Con esto no deseo desestimar otros ejercicios de las ciencias sociales para capturar las experiencias humanas en una época de aceleradas transiciones. Solo subrayo que la investigación histórica no puede restringirse a la definición de un discurso o imaginario que sobrevuela sobre las cabezas o determina tras las espaldas de los actores concretos. Tampoco se limita a diseñar modelos o arquetipos cuyos referentes empíricos son accesorios a la estilizada estructura de una idea. Es cierto que hay en el libro de Touris imaginarios que atraviesan las décadas: el catolicismo integral plasmado en la década de 1930, el mito de la "nación católica", el autoritarismo atribuido a la cultura política peronista, entre otros. Sin embargo, como historiadora practicante, Touris percibe que las acciones de los sujetos históricos no se ajustan sin residuos a esos esquemas, pues 
si no se los sitúa en actores con nombre y apellido, con ubicaciones sociales, políticas y culturales que no permanecen iguales a sí mismas a lo largo del tiempo, son entelequias ajenas a las experiencias concretas de los inciertos asuntos humanos.

La constelación tercermundista es un libro parteaguas en la bibliografía especializada. Incorpora perspectivas teóricas y metodológicas que lo tornan valioso para un público lector argentino, para un interés latinoamericano, pero también del Norte Global, pues proporciona una interpretación de las eficacias del Concilio Vaticano II en una especificidad local que posee sus propios rasgos. Por eso mismo, el libro aquí reseñado no es solo una historia particular del tercermundismo religioso argentino. Es una contribución a la historia de las décadas de 1960 y 1970 en la Argentina, de utilidad comparativa para otras historias nacionales.

Las hipótesis más abarcativas plantean preguntas abiertas. Así ocurre con la idea de un retorno, a través del tercermundismo católico, del "cristianismo peronista". El argumento de la historiadora argentina otorga un lugar preeminente en su explicación a la actuación del sacerdote Hernán Benítez, particularmente en la misa ofrecida junto a Carlos Mugica en ocasión del funeral de dos fundadores de Montoneros abatidos en un enfrentamiento con la policía. Benítez, cercano a Eva Perón, es una figura central en el cristianismo peronista identificado por Lila Caimari. No obstante, en los tardíos años sesenta y tempranos años setenta, la ausencia de Eva Perón, la mayor distancia con el Estado y "el poder", la aparición de planteos del "socialismo nacional", el desinterés de Perón por estas cuestiones (tal vez aprendida la lección de la crisis de 1954-1955), configuran un escenario bien distinto que hace vacilar la reedición del concepto.

Otras de la hipótesis centrales sostiene un desencuentro entre tradicionalismo y modernidad. Según ya he señalado, Touris no se satisface con una dicotomía sencilla donde los actores, instituciones e ideas se ubican claramente en alguna de las columnas opuestas. Justamente, allí reside una de las contradicciones del MSTM: por lado, el mesianismo por "los pobres", sea que se verifique en la lealtad al líder Perón, 
sea que opte por una salida revolucionaria más allá del peronismo; por otro lado, un clericalismo vertical y un culturalismo populista antimoderno. Se trata, de categorías -esto es, de construcciones teóricas- con las cuales la investigación histórica procura ordenar el drama de una época compuesta por innumerables datos heterogéneos. La mera descripción de todos los hechos no constituiría un problema, y leo el libro de Touris como una obra comunicable con aquello que Lucien Febvre denomina una "historia-problema". La autora advierte las dificultades de definiciones conceptuales excesivamente estilizadas en materia historiográfica (lo dice a propósito de los usos ingenuos de "secularización", p. 199), pues tal vez más que términos excluyentes puedan ser pensados como pares solidarios, donde todo fenómeno de cambio supone una relación con la tradición, y donde toda performance de tradición incorpora dimensiones de renovación.

Estas reflexiones finales son posibles gracias al excelente libro de historia escrito por Claudia Touris, un clásico inmediato de los estudios históricos y sociales. Regreso al principio: una obra imprescindible. 